\title{
Caution for Anabolic Androgenic Steroid Use: A Case Report of Multiple Organ Dysfunction Syndrome
}

\author{
Shinya Unai MD, Joseph Miessau PA-C MSc, Pawel Karbowski PA-C MSc, Michael Baram MD, \\ Nicholas C Cavarocchi MD, and Hitoshi Hirose MD
}

\begin{abstract}
We report a 42-year-old male amateur body builder and user of anabolic androgenic steroids, who developed ARDS, acute kidney injury, and refractory supraventricular tachycardia. He required extracorporeal membrane oxygenation, continuous veno-venous hemodialysis, and catheter ablation. We believe that long-term anabolic androgenic steroid abuse predisposed the patient to multiple organ dysfunction syndrome, from its immunomodulatory effects in an otherwise healthy patient. Anabolic androgenic steroid use should be part of the history taking process, since it may complicate diagnosis, disease progression, and prognosis. Key words: anabolic androgenic steroid; ARDS; acute kidney injury; multiple organ dysfunction syndrome; extracorporeal membrane oxygenation. [Respir Care 2013;58(12):e159-e163. (C) 2013 Daedalus Enterprises]
\end{abstract}

\section{Introduction}

Use of anabolic androgenic steroids (AAS) has become more common among professional and amateur athletes. The medical consequences of long-term AAS abuse are unclear, but there are reports of AAS abuse resulting in death. ${ }^{1}$ We report a 42 -year-old male amateur body builder and user of AAS, for muscle building, who developed multiple organ dysfunction syndrome and ARDS, and required veno-venous extracorporeal membrane oxygenation (VV-ECMO).

\section{Case Report}

The patient was a 42-year-old male $(180 \mathrm{~cm}, 90 \mathrm{~kg}$, body mass index $27.8 \mathrm{~kg} / \mathrm{m}^{2}$ ) amateur body builder with a

\footnotetext{
The authors are affiliated with the Division of Cardiothoracic Surgery, Department of Surgery, with the exception of Dr Baram, who is affiliated with the Division of Pulmonary and Critical Care Medicine, Department of Medicine, Thomas Jefferson University, Philadelphia, Pennsylvania.

The authors have disclosed no conflicts of interest.

Correspondence: Hirose Hitoshi MD, Division of Cardiothoracic Surgery, Department of Surgery, Thomas Jefferson University, 1025 Walnut Street, Room 605, Philadelphia PA 19107. E-mail: Hitoshi.Hirose@ jefferson.edu.
}

DOI: $10.4187 /$ respcare. 02338 previous history of smoking but no other noteworthy medical history. He admitted to injecting himself with AAS complexes, including testosterone acetate, testosterone cypionate, testosterone decanoate, testosterone propionate, testosterone phenylpropionate, testosterone enanthate, and testosterone isocaproate, for a few years. He presented to a local emergency room during the summer of 2012, with complaints of nausea, vomiting, diarrhea, and 5 days of shortness of breath and productive cough. He was hypoxic and had episodes of supraventricular tachycardia and rapid atrial flutter (ventricular rate 160-200 beats/min). He was volume resuscitated, and pharmacologic anti-arrhythmic therapy was initiated, but he was unable to maintain sinus rhythm. The initial diagnosis was "pneumonia," and he was started on a standard dose of ampicillin/sulbactam, vancomycin, and moxifloxacin.

$\mathrm{He}$ became profoundly hypoxic and was intubated on the following morning. Arterial blood gas analysis showed $\mathrm{P}_{\mathrm{aO}_{2}} / \mathrm{F}_{\mathrm{IO}_{2}}$ of $76 \mathrm{~mm} \mathrm{Hg}$, and he was diagnosed with ARDS. Despite optimal ventilator support, he was unable to be adequately oxygenated, and was transferred to our hospital for further management. Upon arrival he was afebrile, in normal sinus rhythm (heart rate 80 beats/min), and his blood pressure was 111/50 mm Hg. His blood pressure dropped shortly after admission, and he required 0.5 $1.3 \mu \mathrm{g} / \mathrm{kg} / \mathrm{min}$ of phenylephrine to stabilize his hemodynamics. Physical exam was notable for massive edema and poor air movement. Chest x-ray revealed bilateral infiltrates (Fig. 1). He was placed on continuous mandatory 


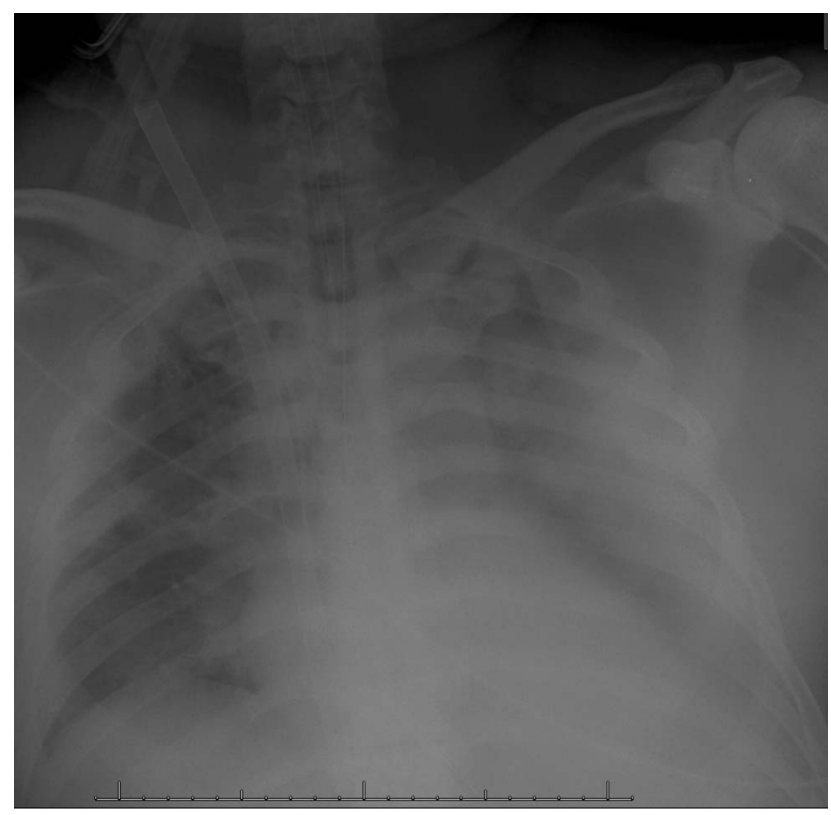

Fig. 1. Chest x-ray on admission shows bilateral infiltrates. ventilation, an $\mathrm{F}_{\mathrm{IO}_{2}}$ of 1.0, and PEEP of $15 \mathrm{~cm} \mathrm{H}_{2} \mathrm{O}$. Arterial blood gas analysis found $\mathrm{pH} 7.26, \mathrm{P}_{\mathrm{CO}_{2}} 40 \mathrm{~mm} \mathrm{Hg}$, $\mathrm{P}_{\mathrm{aO}_{2}} 67 \mathrm{~mm} \mathrm{Hg}$, base deficit $8.2 \mathrm{mEq} / \mathrm{L}$, and arterial oxygen saturation $88 \%$. The peak airway pressure was $36 \mathrm{~cm} \mathrm{H}_{2} \mathrm{O}$. The Table shows the course of his laboratory values and ventilation modes. Urine toxicology screen test was negative. Echocardiography showed normal systolic and diastolic left and right ventricular function and no evidence of intra-cardiac shunt or valvular disease. Abdominal ultrasound was normal.

Due to profound hypoxia, VV-ECMO was initiated with a 27 French Avalon dual cannula (Avalon Laboratories, Rancho Dominguez, California). He was placed on low tidal volume (4-6 mL/kg ideal body weight) ventilation, based on the ARDS Network protocol, ${ }^{2}$ and the plateau airway pressure was kept at $20-25 \mathrm{~cm} \mathrm{H}_{2} \mathrm{O}$. His oxygenation was controlled with ECMO, aiming at upper extremity arterial saturation above $85 \%$. Cerebral saturation was kept over $50 \%$, measured via tissue oximetry (Fore-Sight, Casmed, Branford, Connecticut) to ensure cerebral perfusion. ${ }^{3}$ The antibiotic regimen was changed to piperacillin/tazobactam, $3.375 \mathrm{~g}$ intravenous every 8 hours,

Table. Laboratory and Ventilation Values

\begin{tabular}{|c|c|c|c|c|c|c|c|}
\hline & $\begin{array}{c}\text { Admission } \\
\text { at Outside } \\
\text { Hospital }\end{array}$ & $\begin{array}{l}6 \text { Hours } \\
\text { After } \\
\text { Intubation }\end{array}$ & $\begin{array}{l}\text { Admission } \\
\text { to Our } \\
\text { Hospital }\end{array}$ & $\begin{array}{c}\text { After } \\
\text { Initiation } \\
\text { of ECMO }\end{array}$ & $\begin{array}{c}\text { After } \\
3 \text { Days } \\
\text { of ECMO }\end{array}$ & $\begin{array}{c}1 \text { Day } \\
\text { After ECMO } \\
\text { Decannulation }\end{array}$ & $\begin{array}{c}\text { At } \\
\text { Discharge }\end{array}$ \\
\hline White blood cells, 1,000 cells $/ \mu \mathrm{L}$ & 12.5 & 8 & 10.8 & 12.2 & 25.6 & 14.7 & 16.8 \\
\hline Hemoglobin, g/dL & 16.2 & 13.4 & 13.2 & 11.1 & 9.9 & 9.7 & 8.7 \\
\hline Hematocrit, \% & 45.7 & 39.5 & 40.7 & 34.6 & 29.5 & 27.9 & 26.5 \\
\hline Platelets, $1,000 / \mu \mathrm{L}$ & 246 & 206 & 185 & 231 & 234 & 131 & 454 \\
\hline $\mathrm{F}_{\mathrm{IO}_{2}}$ of ventilator & 1.0 & 1.0 & 1.0 & 1.0 & 0.50 & 0.60 & 0.21 \\
\hline Ventilation mode & Non-rebreathing mask & CMV & CMV & CMV & CMV & CMV & Room air \\
\hline PEEP & 0 & 5 & 15 & 10 & 10 & 12 & \\
\hline $\mathrm{F}_{\mathrm{IO}_{2}}$ of ECMO & & & & 1.0 & 0.60 & & \\
\hline $\mathrm{pH}$ & 7.56 & 7.37 & 7.26 & 7.39 & 7.38 & 7.39 & \\
\hline $\mathrm{P}_{\mathrm{CO}_{2}}, \mathrm{~mm} \mathrm{Hg}$ & 25.5 & 40.7 & 40 & 44 & 48 & 43 & \\
\hline $\mathrm{P}_{\mathrm{O}_{2}}, \mathrm{~mm} \mathrm{Hg}$ & 50 & 76 & 67 & 81 & 104 & 69 & \\
\hline $\mathrm{HCO}_{3}, \mathrm{mEq} / \mathrm{L}$ & 23 & 23 & 18 & 26 & 28 & 26 & \\
\hline Base excess, $\mathrm{mEq} / \mathrm{L}$ & 3 & -1 & -8.2 & 1.8 & 3.1 & 1.3 & \\
\hline $\mathrm{S}_{\mathrm{pO}_{2}}, \%$ & 91 & 93 & 88 & 96 & 98 & 93 & 98 \\
\hline $\mathrm{Na}, \mathrm{mEq} / \mathrm{L}$ & 135 & 139 & 140 & 144 & 137 & 137 & 137 \\
\hline $\mathrm{K}, \mathrm{mEq} / \mathrm{L}$ & 4 & 4.4 & 5.5 & 4.8 & 4.7 & 3.8 & 3.8 \\
\hline $\mathrm{Cl}, \mathrm{mEq} / \mathrm{L}$ & 97 & 104 & 108 & 109 & 105 & 101 & 102 \\
\hline Blood urea nitrogen, $\mathrm{mg} / \mathrm{dL}$ & 20 & 27 & 49 & 52 & 23 & 39 & 35 \\
\hline Creatinine, $\mathrm{mg} / \mathrm{dL}$ & 1.57 & 2 & 3.8 & 4.1 & 2.7 & 2.4 & 2.2 \\
\hline Glucose, mg/dL & 131 & 151 & 172 & 170 & 134 & 87 & 98 \\
\hline Total bilirubin, $\mathrm{mg} / \mathrm{dL}$ & 3.4 & 0.3 & ND & 0.4 & 0.7 & 1.3 & 0.9 \\
\hline Aspartate aminotransferase, IU/L & 58 & 46 & ND & 2335 & 94 & 53 & 16 \\
\hline Alanine aminotransferase, IU/L & 109 & 67 & ND & 1458 & 387 & 159 & 24 \\
\hline Lactate, $\mathrm{mmol} / \mathrm{L}$ & 1.9 & 0.7 & 2.2 & 2.3 & 1.0 & 1.2 & \\
\hline
\end{tabular}




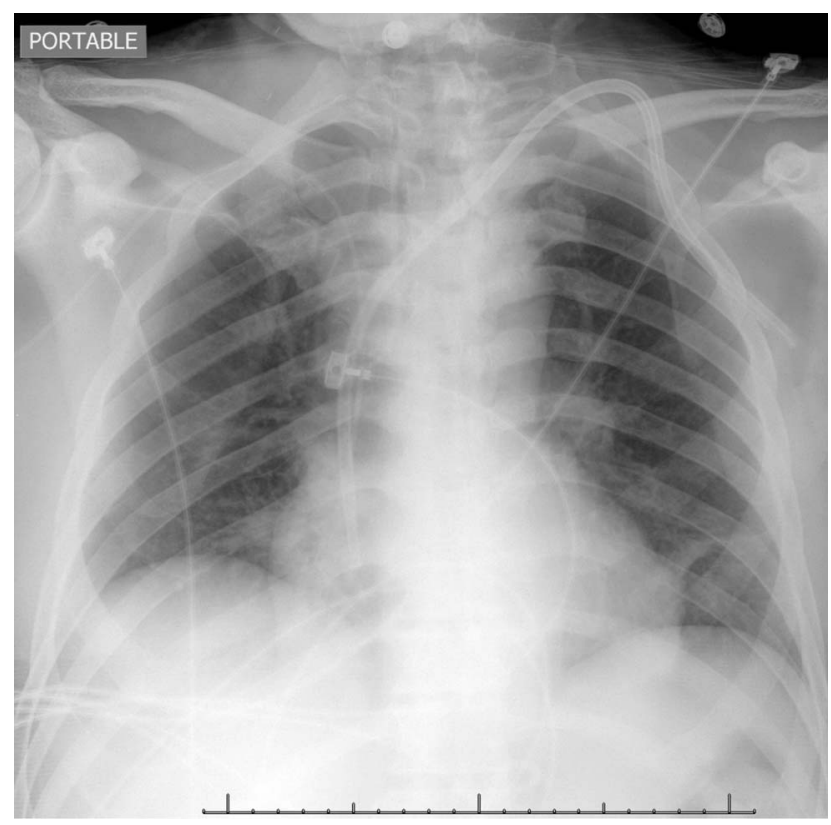

Fig. 2. Chest $\mathrm{x}$-ray before discharge shows clear lung fields.

and moxifloxacin, $400 \mathrm{mg}$ intravenous four times a day. He was oliguric and massively volume overloaded, and was diagnosed with acute kidney injury, and continuous veno-veno hemodialysis was initiated for fluid removal. Multiple cultures of blood, bronchial lavage fluid, and urine, including those from the outside hospital before antibiotic therapy was initiated, were negative, as were human immunodeficiency virus $1 / 2$ antibody, virus polymerase chain reaction for influenza $\mathrm{A}, \mathrm{B} /$ parainfluenza 1-3/rhinovirus/enterovirus/metapneumovirus/adenovirus/ respiratory syncytial virus, hepatitis B surface antigen, hepatitis C antibody, and antigen tests for Legionella pneumophila and Streptococcus pneumoniae; thus antibiotics were discontinued on day 7 .

His respiratory status and chest x-ray gradually improved (Fig. 2), and VV-ECMO was discontinued on day 7, at which time arterial blood analysis found $\mathrm{pH} 7.39$, $\mathrm{P}_{\mathrm{CO}_{2}} 43 \mathrm{~mm} \mathrm{Hg}, \mathrm{P}_{\mathrm{aO}_{2}} 69 \mathrm{~mm} \mathrm{Hg}$, and arterial oxygen saturation $93 \%$, while on continuous mandatory ventilation with $\mathrm{F}_{\mathrm{IO}_{2}}$ 0.60, and PEEP $12 \mathrm{~cm} \mathrm{H}_{2} \mathrm{O}$. He started to make urine, and continuous veno-venous hemodialysis was discontinued on day 9, and intermittent hemodialysis was discontinued on day 11 .

During his hospital stay he had multiple episodes of supraventricular tachycardia and atrial flutter. A diltiazem/ amiodarone protocol was initiated and intravenous metoprolol was given, but he failed to maintain sinus rhythm. Electrical cardioversion and adenosine were able to convert to sinus rhythm, but he soon returned to supraventricular tachycardia or atrial flutter. After his oxygenation improved, he was taken to the electrophysiology lab and cava tricuspid isthmus was ablated for atrial flutter. After- wards, further electrophysiology studies were performed, but supraventricular tachycardia was not able to be induced, so no additional ablation was done. He was placed on oral amiodarone and diltiazem, and was able to maintain sinus rhythm afterwards. Tracheostomy was performed on day 20 , due to ventilator dependence. He came off the ventilator on day 27. Nausea and vomiting persisted during the hospital stay, but resolved gradually. The tracheostomy was removed prior to discharge to home, on day 38 .

\section{Discussion}

The use of AAS among professional athletes and bodybuilders has been reported since the 1950s. ${ }^{4}$ Gradually it became more popular among recreational and nonprofessional bodybuilders. In the 1980s AAS gained popularity among young males to increase muscle mass and physical appearance. ${ }^{5}$ Currently, AAS use has spread to casual fitness enthusiasts and sub-elite sportsmen and sportswomen, since AAS can be obtained via the Internet, without a prescription. It is estimated that there are 3 million AAS users in the United States, and the lifetime prevalence of AAS use is $0.9 \%$ in males and $0.1 \%$ in females in the general population. ${ }^{5}$

The medical effects of long-term AAS abuse are unclear. The known common side effects include acne, testicular atrophy, gynecomastia, and pain at the injection site. Erectile dysfunction and libido loss may also occur. ${ }^{6}$ Nausea and vomiting, as seen in our patient, have been reported in several case reports. ${ }^{6,7}$ The mechanism of the chronic nausea and vomiting can be related to hypercalcemia induced by the AAS, ${ }^{8}$ but that was not seen in our patient. Other less common but severe side effects include cardiovascular complications, hepatic dysfunction, acute kidney injury, psychiatric disorders, reduction of thyroid hormone production, infertility, and immunomodulatory effects. ${ }^{69}$ Mortality risk among chronic AAS users is estimated to be 4.6 times higher than that in the normal age-adjusted population. ${ }^{4}$

Herr et al reported a 30-year-old bodybuilder who developed ARDS secondary to sepsis from an abscess at the injection site. ${ }^{10}$ Herr suggested that the long-term use of AAS caused immunosuppression and resulted in sepsis in an otherwise healthy patient. In our patient, despite extensive workup, the etiology of the ARDS remained unknown. One differential diagnosis was aspiration pneumonia caused by persistent nausea and vomiting. Elevated white blood cell count and procalcitonin suggested bacterial infection, but all the cultures were negative. Voigt et al reported that a respiratory syncytial virus infection resulted in ARDS in an adult patient with human immunodeficiency virus. ${ }^{11} \mathrm{~A}$ viral infection may have been the cause of our patient's nausea, vomiting, and diarrhea prior to the hospital visit, and he may have had a micro-aspiration during those symp- 
toms. It is possible that the combination of an undetected viral infection and aspiration caused sepsis that was worsened by the immunosuppressive effect of long-term AAS abuse, which led to ARDS. Injection of supraphysiologic concentrations of AAS suppresses natural killer cell activity and lymphocyte development into effector and memory cells, which decreases antibody sensitivity and secretion, resulting in immunosuppression. ${ }^{9}$

The treatment of ARDS consists of fluid management, lung-protective ventilation with low tidal volume and moderate PEEP, multi-organ support, and treatment of the underlying cause. ECMO is indicated for ARDS with severe hypoxemia $\left(\mathrm{P}_{\mathrm{aO}_{2}} / \mathrm{F}_{\mathrm{IO}_{2}} \leq 80 \mathrm{~mm} \mathrm{Hg}\right.$, despite high PEEP), uncompensated respiratory acidosis $\left(\mathrm{pH}<7.15, \mathrm{P}_{\mathrm{aCO}_{2}}\right.$ $>60 \mathrm{~mm} \mathrm{Hg}$ ), and/or unable to tolerate conventional mechanical ventilation. ${ }^{12}$ The Avalon cannula is designed for VV-ECMO, drawing de-oxygenated blood from the superior/inferior vena cava and returning oxygenated blood toward the tricuspid valve. Contraindications to the Avalon cannula include intracardiac shunt and other general contraindications to ECMO, such as intracranial bleeding.

A few reports have shown a possible relationship between AAS use and altered cardiac electrical activity. Steroids may increase the rate of cardiac repolarization and shorten the QT interval. ${ }^{1}$ Myocardial structural and molecular remodeling induced by AAS have also been reported, and can lead to severe atrial arrhythmia, ${ }^{13}$ as observed in our patient. Other cardiovascular complications in AAS users are acute myocardial infarction related to premature atherosclerosis caused by increased low-density lipoprotein cholesterol and decreased high-density lipoprotein cholesterol. ${ }^{4}$ There is an increased risk of arterial and pulmonary embolism, due to elevated hemoglobin level. ${ }^{1}$ Additionally, impaired left-ventricular systolic and diastolic function may develop secondary to direct toxic effects on myocytes, endothelial cells, and/or increased collagen cross-links between myocytes. The mechanism of AAS-induced arrhythmia remains unknown.

Serum creatinine level is proportional to body muscle mass, and those who have well-developed musculature may have higher baseline serum creatinine, dependent on clearance. Acute kidney injury can be caused by dehydration and rhabdomyolysis caused by strenuous exercise; use of non-steroidal anti-inflammatory drugs to ease musculoskeletal pain caused by exercise; or use of diuretics to reduce weight, maintain muscular body habitus, or to clear banned substances.

Daher reported 2 cases of AAS-related interstitial nephritis causing acute kidney injury. ${ }^{6}$ Habscheid and Yoshida separately reported a type of AAS (stanozolol) causing cholestasis that resulted in acute kidney injury in an otherwise healthy young male. ${ }^{14,15}$ They thought that AAS abuse triggered cholestasis and jaundice, which subsequently decreased systemic vascular resistance and caused hypotension and hypoperfusion of the kidney, leading to acute kidney injury. In our patient the acute kidney injury may have been due to the combination of persistent hypoxia and septic condition.

Our patient's liver enzymes were only slightly elevated when he presented at the emergency room at the local hospital, but were elevated when he was transferred to our hospital. We believe this transient liver dysfunction was related to the combination of hypoxia and septic conditions, rather than direct toxicity from AAS. Although his echocardiography was normal, multiple episodes of supraventricular tachycardia, massive fluid resuscitation for low blood pressure, and acute kidney injury and low urine output may have resulted in fluid overload and hepatic congestion. His amino-terminal pro-brain natriuretic peptide was mildly elevated upon admission to the local hospital $(917.8 \mathrm{pg} / \mathrm{mL})$, and pleural effusion on ultrasound supports that hypothesis. However, it would be unusual if the cause of hypoxia were cardiogenic pulmonary edema, since he was rather dehydrated and hypovolemic when he arrived at the outside hospital, and echocardiography showed good left-ventricular function. The liver enzymes quickly improved after correction of the volume status and initiation of VV-ECMO and continuous veno-venous hemodialysis.

The relationship between AAS use and multi-organ dysfunction is not completely clear in our patient, but we believe that his long history of AAS abuse played a crucial role in causing the systemic inflammatory response and multiple-organ dysfunction in this otherwise healthy patient.

\section{REFERENCES}

1. Angell P, Chester N, Green D, Somauroo J, Whyte G, George K. Anabolic steroids and cardiovascular risk. Sports Med 2012;42(2): 119-134.

2. Thompson BT, Bernard GR. ARDS Network (NHLBI) studies: successes and challenges in ARDS clinical research. Crit Care Clin 2011;27(3):459-468.

3. Wong JK, Smith TN, Pitcher HT, Hirose H, Cavarocchi NC. Cerebral and lower limb near-infrared spectroscopy in adults on extracorporeal membrane oxygenation. Artif Organs 2012;36(8):659-667.

4. Kanayama G, Hudson JI, Pope HG Jr. Long-term psychiatric and medical consequences of anabolic-androgenic steroid abuse: a looming public health concern? Drug Alcohol Depend 2008;98(1-2):1-12.

5. Hakansson A, Mickelsson K, Wallin C, Berglund M. Anabolic androgenic steroids in the general population: user characteristics and associations with substance use. Eur Addict Res 2012;18(2):83-90.

6. Daher EF, Silva Junior GB, Queiroz AL, Ramos LM, Santos SQ, Barreto DM, et al. Acute kidney injury due to anabolic steroid and vitamin supplement abuse: report of two cases and a literature review. Int Urol Nephrol 2009;41(3):717-723. 


\section{Caution for Anabolic Androgenic Steroid Use}

7. Geraci MJ, Cole M, Davis P. New onset diabetes associated with bovine growth hormone and testosterone abuse in a young body builder. Hum Exp Toxicol 2011;30(12):2007-2012.

8. Samaha AA, Nasser-Eddine W, Shatila E, Haddad JJ, Wazne J, Eid AH. Multi-organ damage induced by anabolic steroid supplements: a case report and literature review. J Med Case Rep 2008;2:340.

9. Brenu EW, McNaughton L, Marshall-Gradisnik SM. Is there a potential immune dysfunction with anabolic androgenic steroid use? A review. Mini Rev Med Chem 2011;11(5):438-445.

10. Herr A, Rehmert G, Kunde K, Gust R, Gries A. A thirty-year old bodybuilder with septic shock and ARDS from abuse of anabolic steroids. Anaesthesist 2002;51(7):557-563.

11. Voigt E, Tillmann RL, Schewe JC, Molitor E, Schildgen O. ARDS in an HIV-positive patient associated with respiratory syncytial virus. Eur J Med Res 2008;13(3):131-132.

12. Brodie D, Bacchetta M. Extracorporeal membrane oxygenation for ARDS in adults. N Engl J Med 2011;365(20):1905-1914.

13. Lau DH, Stiles MK, John B, Shashidhar, Young GD, Sanders P. Atrial fibrillation and anabolic steroid abuse. Int J Cardiol 2007; 117(2):e86-e87.

14. Yoshida EM, Karim MA, Shaikh JF, Soos JG, Erb SR. At what price, glory? Severe cholestasis and acute renal failure in an athlete abusing stanozolol. CMAJ 1994;151(6):791-793.

15. Habscheid W, Abele U, Dahm HH. [Severe cholestasis with kidney failure from anabolic steroids in a body builder]. Dtsch Med Wochenschr 1999;124(36):1029-1032. Article in German. 